\title{
ALGORITHMIC BIAS AND MĀORI
}

He Rourou, Volume 1, Issue 1, 93-94, 2021

SARA STRATTON AND JONI ANGELI-GORDON

In this kōrero Sara Stratton (Ngāti Hine, Ngāti Kahu) shares her recent research on algorithmic bias and Māori with Joni Angeli-Gordon (Ngāpuhi, Ngāti Whātua, Te Roroa). Listen using the audio player below (web version only) or follow this link.

1 An audio element has been excluded from this version of the text. You can listen to it online here: https://herourouv1.pressbooks.com/?p=56

An audio transcript is available here

You can find out more about Sara's work at www.maorilab.maori.nz

The opinions expressed are those of the paper author(s) and not He Rourou or The Mind Lab.

He Rourou by The Mind Lab is licensed under a Creative Commons Attribution-NonCommercial-ShareAlike 4.0 International License, except where otherwise noted. [ISSN 2744-7421]

\section{About the Authors}

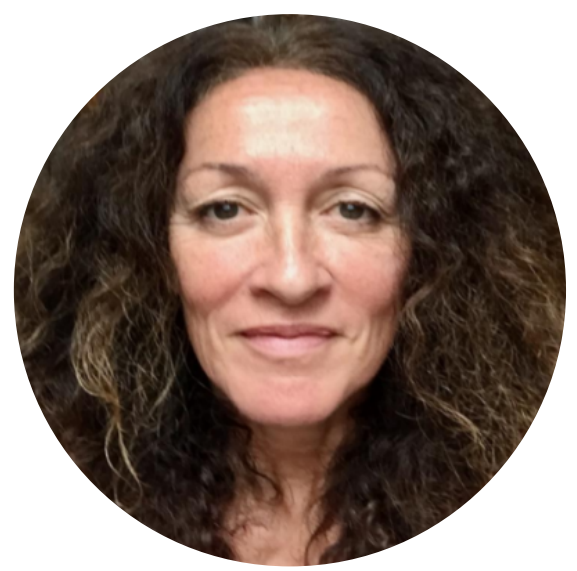

Sara Stratton

Sara Stratton is founder of Māori Lab - Ngāti Hine, Ngāti Kahu - Our Know-how, Know-WHY creates inclusive, sustainable futures. Bringing Māori Cultural Transformation to companies and 
organisations.

World Economic Forum: Global future's Council; AI for Humanity, Oct 2020-Oct 2022

Master's of Technological Futures: Tech Futures Lab - 2019-2020

Law degree: Auckland University 1998

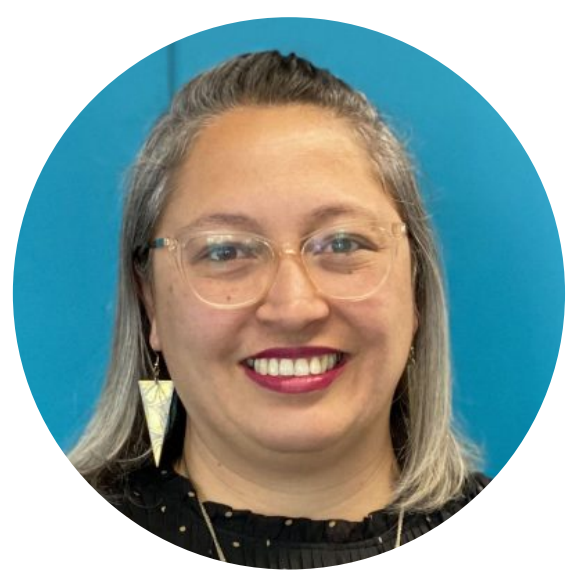

Joni Angeli-Gordon

Joni Māramatanga Angeli-Gordon has tribal connections to Northland, Kaipara and Tāmaki Mākaurau (Ngāpuhi / Ngāti Whātua). She has a background in education as a secondary teacher for 11 years in English medium and Māori medium settings. Since leaving the classroom, she has been in the tertiary space in a range of teaching and academic roles. She is presently a research advisor at Te Wānanga o Aotearoa and completing a $\mathrm{PhD}$ at the University of Waikato and is the director of a boutique indigenous consultancy called Mauri Aroha. Her main research themes include indigenous concepts of mindfulness, Māori medium education, and Māori pedagogies. You can contact Joni at joni.angeli-gordon@themindlab.com 